\title{
Continuous and intermittent exposure to the hypoxia of altitude: implications for glutamine metabolism and exercise performance
}

\author{
D M Bailey, L M Castell, E A Newsholme, B Davies
}

Although most elite athletes invest a considerable amount of time and resources training at altitude, the practical benefits gained remain to be clearly established despite almost half a century of investigation. Elucidating the potential factors that affect physical performance after return to sea level has been the subject of much interest and controversy.

The time spent exposed to the hypoxia of altitude would appear to be an important mediator of sea level performance. A combination of physical exercise and intermittent hypoxia (defined as an exposure time of 30 minutes to 12 hours a day) has been shown to accelerate the normal adaptations invoked by a comparable programme of normoxic training with cardioprotective and performance enhancing benefits. ${ }^{1}$ In contrast, increased free radical mediated oxidative stress, ${ }^{2}$ decreased cell mediated immunity, ${ }^{3}$ and increased incidence of infectious episodes ${ }^{4}$ have been reported in continuous hypoxia (defined as an exposure time of 24 hours a day). We have previously reported two cases of infectious mononucleosis following chronic exposure to $1500-2000 \mathrm{~m}^{5}$

Glutamine has been identified as a conditionally essential amino acid required for lymphocyte proliferation and macrophage phagocytosis, and it has been suggested that any physiological decrease in plasma glutamine may impair the host's defence against opportunistic infections. ${ }^{6}$ In the light of these findings, we examined changes in plasma glutamine, the incidence of overt physical illness, and maximal exercise performance as a function of continuous and intermittent hypoxic training at comparable inspiratory partial pressures of oxygen $\left(\mathrm{PIO}_{2}\right)$ or simulated altitudes.

\section{Methods \\ SUBJECTS \\ After ethical approval, volunteers were solicited from two separate cohorts of international standard endurance runners (continuous group, $\mathrm{n}=22$ ) and endurance trained univer- sity students (intermittent group, $\mathrm{n}=32$ ).}

EXPERIMENTAL DESIGN

In study 1 (continuous group), 22 elite distance runners had the option of spending four weeks at an altitude training camp based at $1640 \mathrm{~m}$ in Johannesburg, South Africa $\left(\mathrm{PIO}_{2}=\right.$ 122 (1) $\mathrm{mm} \mathrm{Hg}$ ). Of these, 10 volunteers travelled to altitude (continuous $\mathrm{ExP}_{\mathrm{P}}$ ) and 12 trained at sea level in the United Kingdom $\left(\mathrm{PIO}_{2}=151\right.$ (3) $\mathrm{mm} \mathrm{Hg}$; continuous $\left.{ }_{\mathrm{CON}}\right)$. Although it was not possible to randomly assign volunteers to the altitude or sea level training camps, retrospective analysis identified that the two subgroups drawn from a homogeneous group of distance runners had comparable performance capabilities.

In study 2 (intermittent group), 18 volunteers were randomly assigned in a double blind manner to train for four weeks in a laboratory inspiring a medical grade normobaric hypoxic gas $\left(\mathrm{PIO}_{2}=115\right.$ (2) mm Hg; intermittent $\left.{ }_{\mathrm{EXP}}\right)$, and 14 performance matched volunteers trained while exposed to normobaric normoxia $\left(\mathrm{PIO}_{2}=150\right.$ (2) $\mathrm{mm} \mathrm{Hg}$; intermittent $\left.{ }_{\mathrm{CON}}\right)$. These gases were designed to approximate the $\mathrm{PIO}_{2}$ experienced in study 1 .

All volunteers performed a standardised exercise test in normobaric normoxia before and after training for the determination of maximal aerobic capacity $\left(\dot{\mathrm{V}}_{2} \mathrm{MAX}\right)$. The incidence of physical symptoms associated with an upper respiratory tract or gastrointestinal tract illness was assessed, and resting venous blood samples were analysed for a differential white blood cell count and plasma glutamine.

HYPOXIC/NORMOXIC TRAINING PROGRAMMES Both the normoxic and hypoxically trained subgroups performed the same volume of physical training at the same percentage of heart rate maximum, which was enforced using electrocardiograph calibrated bipolar telemetry (Vantage, Polar Electro, Oy, Finland).

STATISTICAL ANALYSIS

Changes in selected dependent variables as a function of timing (before $v$ altitude $v$ after) and group (exposure to hypoxia (EXP) $v$ controls (CON)) were analysed using a two factor mixed analysis of variance. After a significant interaction and simple main effects, a posteriori comparisons within groups were analysed using Bonferroni paired samples $t$ tests. Simple effects between groups were assessed using a one way analysis of variance and a Tukey honestly significant test. The $\alpha$ level was set at $\mathrm{p}<0.05$ for all two tailed tests, and values are reported as means (SD).

\section{Results}

A considerable increase in the incidence of respiratory tract or gastrointestinal tract illness was observed during continuous exposure to the hypoxia of terrestrial altitude (fig 1). This was accompanied by a decrease in plasma glutamine (fig 2), which was more pronounced in those volunteers presenting with an illness than in those who remained apparently healthy $(-182$ (38) $\mu \mathrm{mol} / 1$ v -92 (32) $\mu \mathrm{mol} / 1 ; \mathrm{p}<0.05)$. Plasma 


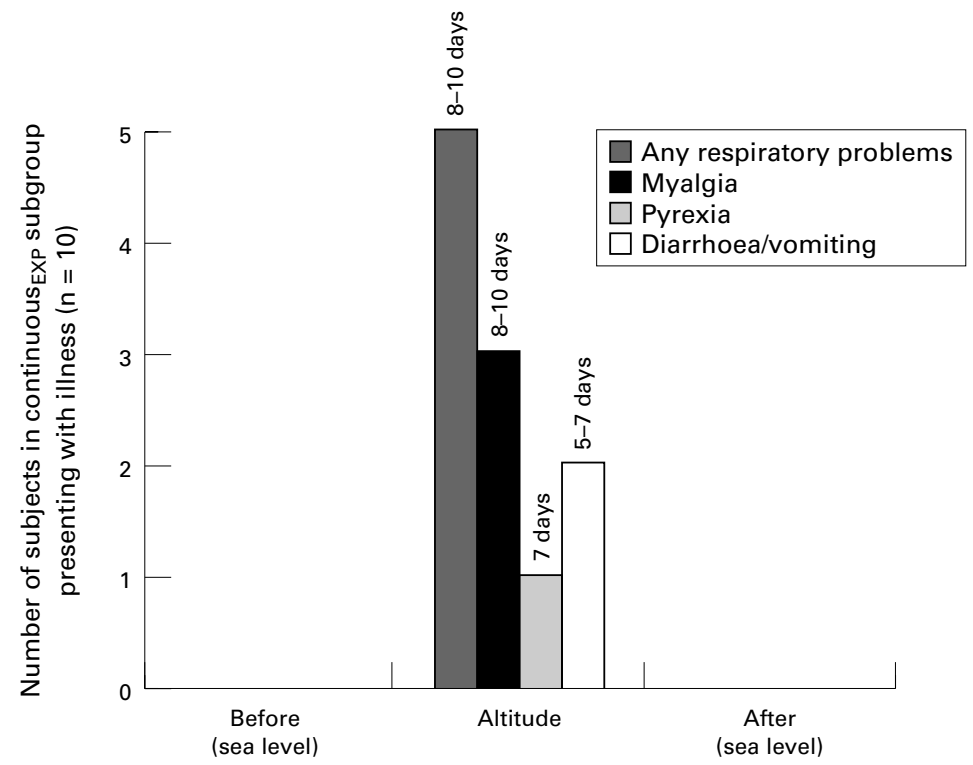

Figure 1 Incidence and duration (in days) of illnesses encountered at sea level and during continuous exposure to $1640 \mathrm{~m}$. Any respiratory problems indicates any two of the following symptoms: sore throat, cough, runny nose, sinusitis, earache.

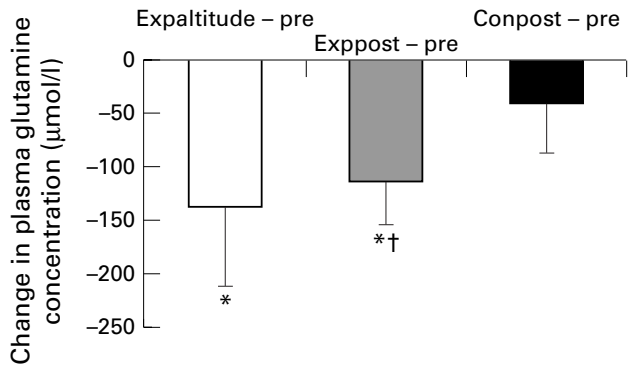

Figure 2 Changes (values found at altitude or after return to sea level minus the value found before) in the resting concentration of plasma glutamine during and after continuous hypoxic training. Pre, altitude, and post indicate values obtained before, during (day 19 at $1640 \mathrm{~m}$ ), and after continuous hypoxic (exp)/normoxic (con) training. *Significant difference from within subgroup value $(p<0.05)$. HSignificant difference between groups $(p<0.05)$.

glutamine concentration remained depressed and total white blood cell count decreased after return to sea level (table 1), whereas no changes were observed for $\dot{\mathrm{V}}_{2} \mathrm{MAX}$. In contrast, fig 3 illustrates the increase in plasma glutamine $(+78$ (109) $\mu \mathrm{mol} / 1, \mathrm{p}<0.05)$ and $\dot{\mathrm{VO}}_{2} \mathrm{MAX}(+0.47$ (0.77) litres/min, $\mathrm{p}<0.05)$ invoked by intermittent hypoxia, whereas changes in the differential white blood cell count (table 1) and the incidence of illness were unremarkable.

Table 1 Differential white blood cell count before, during, and after continuous/ intermittent hypoxic training

\begin{tabular}{|c|c|c|c|}
\hline Group/subgroup & White blood cells $\left(10^{9} / \mathrm{l}\right)$ & Lymphocytes $\left(10^{9} / l\right)$ & Neutrophils $\left(10^{9} / \mathrm{l}\right)$ \\
\hline Continuous $\mathrm{PRE}_{\mathrm{EXP}}$ & $5.02(1.51)$ & $1.4(0.5)$ & $3.0(0.9)$ \\
\hline ALTITUDE $_{\mathrm{EXP}}$ & $6.50(1.60)$ & $1.7(0.4)$ & $3.9(1.0)$ \\
\hline $\operatorname{POST}_{\text {EXP }}$ & $3.72(1.35)^{\star}$ & $1.5(0.5)$ & $2.6(1.0)$ \\
\hline $\mathrm{PRE}_{\mathrm{CON}}$ & $4.84(0.74)$ & $1.5(0.4)$ & $2.7(0.7)$ \\
\hline POST $_{\mathrm{CON}}$ & $4.07(0.95)$ & $1.6(0.9)$ & $2.4(1.0)$ \\
\hline Intermittent $\mathrm{PRE}_{\mathrm{EXP}}$ & $6.2(1.6)$ & $2.0(0.5)$ & $3.6(1.2)$ \\
\hline $\operatorname{POST}_{\mathrm{EXP}}$ & $5.5(1.3) \dagger$ & $2.0(0.7)$ & $2.9(0.9) \dagger$ \\
\hline $\mathrm{PRE}_{\mathrm{CON}}$ & $5.4(1.0)$ & $1.8(0.4)$ & $2.9(1.0)$ \\
\hline $\mathrm{POST}_{\mathrm{CON}}$ & $4.7(0.6) \dagger$ & $1.8(0.4)$ & $2.4(0.4)$ \\
\hline
\end{tabular}

All data expressed as mean (SD). Continuous, continuous exposure; Intermittent, intermittent exposure; ExP, hypoxically trained subgroup; con, normoxically trained subgroup. PRE, before normoxic/hypoxic training; ALTITUDE, determined on day 19 at $1640 \mathrm{~m}$; POST, after normoxic/hypoxic training; ${ }^{\star} \mathrm{p}<0.05$ significantly different from ALTITUDE within subgroup value; $\mathrm{t} p<0.05$ significantly different from within subgroup PRE value.

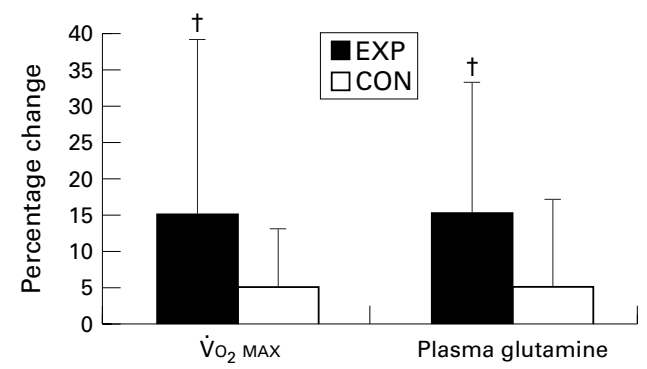

Figure 3 Changes ((beforelafter) $\times 100 \%)$ in the resting concentration of plasma glutamine and $\dot{V}_{O_{2}} M A X$ after intermittent normoxic (CON) and hypoxic (EXP) training. Hignificant difference between groups $(p<0.05)$.

\section{Discussion}

While we acknowledge the limitations imposed by two separate cohorts with different exercise capabilities and the logistical idiosyncrasies of field research, our observations suggest that the duration of the hypoxic stimulus is an important modulator of immune function and physical exercise performance. The appreciable increase in overt physical illness at altitude, either due to the chronicity of hypoxia per se and/or contact with novel infectious pathogens, may suggest possible immunodepression, an observation previously linked to depression of cell mediated immunity. ${ }^{78}$ The decrease in plasma glutamine, which has been shown to decrease both lymphocyte proliferation and response time in vitro, ${ }^{9}$ may be a contributory factor implicated in such a response. However, whether the decrease in glutamine was a cause or a consequence of illness remains to be established.

In contrast, physical illness was not prevalent during intermittent hypoxic training despite a similar $\mathrm{PIO}_{2}$. The increase in $\dot{\mathrm{V}}_{2} \mathrm{MAX}$ appeared to be independent of changes in arterial oxygen content (data not shown) and possibly due to other unquantified central and/or peripheral factors. The increase in plasma glutamine was intriguing and to our knowledge has only previously been anecdotally reported in a review. ${ }^{10}$

In conclusion, a combination of physical exercise and repeated bouts of intermittent hypoxia appears to initiate a disruption in systemic homoeostasis which is followed by an adaptive phase which, in general terms, appears to be beneficial. Adaptation appears to be inadequate during continuous hypoxia, which could have potentially deleterious consequences.

This research was supported by the British Olympic Association, British Athletics Federation, and British Oxygen Company.

1 Bailey DM, Davies, B. Physiological adaptation to environmental hypoxia; implications for exercise performance. In: MacAuley D, ed. Benefits and hazards of exercise. London: BMJ Books, 1999:277-304.

2 Vasankari, TJ, Kujala, UM, Rusko $\mathrm{H}$, et al. The effect of endurance exercise at moderate altitude on serum lipid peroxidation and antioxidative functions in humans. Eur $\mathcal{F}$ Appl Physiol 1997;75:396-9.

3 Meehan RT. Immune suppression at high altitude. Ann Emerg Med 1987;16:974-9.

4 Murdoch DR. Symptoms of infection and altitude illness among hikers in the Mount Everest Region of Nepal. Aviat Space Environ Med 1995;66:148-51.

5 Bailey DM, Davies B, Budgett R, et al. Recovery from infectious mononucleosis following altitude training in an elite middle distance runner. Br 7 Sports Med 1997;31:153-4.

6 Newsholme EA, Parry-Billings M. Properties of glutamine release from muscle and its importance for the immune system. Fournal of Parenteral and Enteral Nutrition 1990;14:
635-75. 
7 Kitayev MI, Tokhtabayev AG. T and B lymphocytes as related to adaptation to high altitudes. Kosm Biol Avia Kosm

8 Mirrakhimov MM, Kitayev MI. Problems and prospects of high-altitude immunology. Vestn Akad Med Nauk SSSR 1979;4:64-9.
9 Parry-Billings $\mathrm{M}$, Evans J, Calder $\mathrm{P}$, et al. Does glutamine contribute to immunosupression after major burns? Lancet contribute to imm

10 Rowbottom DG, Keast D, Morton AR. The emerging role of glutamine as an indicator of exercise stress and overtraining. Sports Med 1996;21:80-97.

\section{Take home message}

The duration of exposure to environmental hypoxia during physical exercise is a potential mediator of immune function and athletic performance. Continuous hypoxic training resulted in overt immunodepression whereas intermittent hypoxic training increased physical exercise performance considerably.

\section{Sports medicine? The ultimate folly}

"Sports medicine? I suppose that means treating frisbee injuries." I am told that this comment was made with a slight sneer and a snort of derision by a consultant orthopaedic surgeon. It reminds me of a similar incident about 12 years ago when I was attending a GP refresher course, and a consultant rheumatologist informed his audience that "there is no such thing as a sports injury". I find such comments sad and not a little frightening. Sad, because they reveal a lack of knowledge, understanding, and a suspiciously closed mind. Frightening because a statement made by an "expert" in this way is taken at face value by the trusting recipients, who, in turn, pass it on, leading to a cascade of misinformation.

Let me set the record straight. I need hardly comment on the reality of sports injuries and the practice of sports medicine; you are already reading this journal. However, I cannot allow the reference to frisbee to pass unanswered! I have been medical advisor to the British Ultimate Federation for 13 years and have seen and treated my fair share of frisbee related injuries in that time. ${ }^{1}$ Ultimate is the team sport played with a "flying disc", and, although there are other disciplines (disc golf, double direct court, guts), it is ultimate that is the most athletic. Ultimate is like a number of other minority sports: fast, exciting, requiring fitness, skill, and team-work, and has organisational structures at national and international level (see the British Ultimate Federation web site at www.ultimateweb.co.uk/buf/). It remains curious (some might say outrageous) that it is consistently denied Sports Council recognition.

Ultimate is played on a pitch $70 \times 30$ yards with an end zone at each end. Teams of seven oppose each other, one team attempting to string together a sequence of passes without the disc going to ground, out of bounds, or being intercepted until a final pass can be made to a team mate who is within the end zone, this being a score. The opposition are attempting to intercept (and thus gain possession) or to mark their oppo-

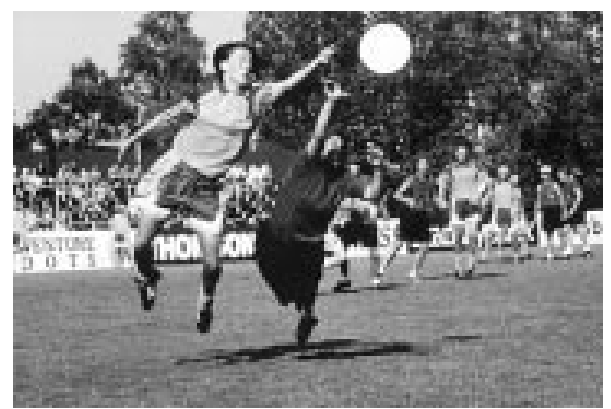

Figure 1 A game of ultimate in progress. Picture courtesy of fonathan Hope.

nent so closely that a pass cannot be made (fig 1). A player cannot run with the disc and has to pass before the end of the stall count set by his/her marker. There are no umpires (the game has a clear set of rules to deal with disputes rapidly) and the overall rule is the "spirit of the game". Games are played to 21 points and can last two hours or more.

Although this is a non-contact game, injury is far from unknown. At the recent World Club Championships in St Andrews, Scotland, 1800 players took part, and I dealt with lacerations, concussion, lateral ligament ankle sprains up to grade $2 / 3$, anterior cruciate ligaments ruptures, fractured metacarpals, fractured radius and ulnar, intraocular haemorrhage, rotator cuff injuries, muscle tears of various grades in just about every leg muscle, all injuries typical of a fast running sport which features rapid changes of direction and diving. Other ultimate injuries have included concussion, a ruptured jejunum, scaphoid fractures, dislocated shoulders, and fibula fractures to mention but a few.

So, Mr Orthopaedic Surgeon, pause for thought before you speak. Not only may you be wrong, you may also have an irate "frisbee" doctor in your audience!

Colchester, Essex

P MARFLEET

1 Ultimate injuries: a survey. $\mathrm{Br} \quad \mathcal{f}$ Sports Med 1991;25:235-240. 